\title{
Impact of Endocrine Disrupting Chemicals (EDCs) on Reproductive Health of Human
}

\author{
Abhinandan Ghosh ${ }^{1} \cdot$ Adrija Tripathy $^{2} \cdot$ Debidas Ghosh $^{2}$
}

Received: 20 August 2021/Revised: 8 November 2021/ Accepted: 11 November 2021/Published online: 6 March 2022

(C) The Author(s) 2022

\begin{abstract}
At present, endocrine disrupting chemicals (EDCs) have gained attention in human pathophysiology, and many studies have yet been conducted to explain the mechanism of these chemical compounds on endocrine and reproductive dysfunctions. In human the maximum studies focus towards the exposure to endocrine disrupting chemicals and their disorders on different endocrine axises though sufficient information are not available on reproductive systems in human. A huge number of EDCs resulting the interference of the normal functions of hypothalamic-pituitary-gonadal axis. There are several types of EDCs like pesticides, heavy metals, food additives and contaminants which are responsible to create negative impact on metabolism and alteration of the homeostasis of tissue and promoting different disorders such as diabetes, obesity, cardiovascular disease, infertility etc. Genomic and nongenomic mechanisms which have been proposed to clarify these complications together with occupational or environmental exposure together, the lack of in depth studies, and the occurrence of different confusing factors have prohibited to establish the causal relationship between the reproductive cum endocrine disorders and exposure to specific EDCs so far. The aim of the manuscript is to review the scientific literature exists so far on the different hazardous effects of EDCs on reproductive health focusing
\end{abstract}

Debidas Ghosh

debidasghosh999@gmail.com

1 Department of Paramedical and Allied Health Sciences, Midnapore City College, Kuturia, Bhadutala, Midnapore, India

2 Molecular Medicine and Nutrigenomics Research Laboratory, Vidyasagar University, Midnapore, West Bengal 721102, India the up to date mode of actions of major EDCs in this concerns.

Keywords Endocrine Disruptive Chemicals · Hormones · Endocrine System - Thyroid · Ovary · Testis · Adrenal Gland · Pituitary Gland · Reproductive System

\section{Introduction}

Human actions have introduced wide varieties of contaminants into the environment globally. These types of contaminants include different categories of organic and inorganic chemical compounds which are endocrine disruptors, natural toxins, disinfection by products (Fiorentino et al. 2017), industrial chemicals, persistent organic pollutants (POPs), lifestyle compounds such as caffeine, brominated flame retardants (BFRs), artificial sweeteners and pesticides which damage human health and biota (Khan et al. 2020). Endocrine-disrupting compounds (EDCs) are also known as endocrine-disrupting chemicals. The intervention executed by a foreign substance with the hormonal system is termed as endocrine disruption and the substances responsible for this aspect are known as endocrine disrupting chemicals (EDCs) (Gronemeyer et al. 2004). As per U.S. Environment Protection Agency (EPA), EDCs is defined as "an exogenous agent that interferes with synthesis, secretion, transport, metabolism, binding action, or elimination of natural blood-borne hormones those are present in the body and are responsible for interfering the homeostasis, reproduction, and developmental process. About 85,000 chemicals are manufactured, of which more than thousands are considered as EDCs. These types of chemicals are also considered as xenobiotic compounds mainly present in toys, plastic bottles, 
detergents, polyvinylchloride pipes, cosmetics, toothpaste (Flint et al. 2012). Endocrine disruptive chemicals (EDCs) remarkably affect the reproductive processes regulated by nuclear receptors (NRs) with special reference to estrogen receptors (ERs) and the androgen receptors through receptor mediated signal transduction system. More specifically, these chemicals bind with endocrine receptors to alter hormone synthesis and degradation. The endocrine disruptors are identified as highly heterogenous in nature (Jackson and Sutton 2008). These compounds are found in the form of nanogram to microgram per litre (ng/L and $\mu \mathrm{g} /$ L) and these are identified in the water with the help of different chemical analytical methods. EDCs enter the body via inhalation, placenta, lactation etc. The chemical compounds create different pathological complications like diabetes, infertility, obesity, neurodegenerative diseases, heart disease, and thyroid dysfunctions by activating, blocking and altering the hormonal functions (Jackson and Sutton 2008). The manuscript aims to review the state of art of scientific literature regarding the effects of EDCs on human physiology in general with special references to reproductive system in direct or indirect manner through negative impact on endocrine systems.

\section{Mechanistic Approach of EDCs}

The nuclear receptors (NRs) focus structurally associated transcriptional factors. About $48 \mathrm{NRs}$ have been identified in mammals which are involved in all the essential functions e.g. homeostasis, fetal development, metabolism, reproduction etc. These EDCs bind and activate various nuclear receptors such as pregnane $\mathrm{X}$ receptor, androgen receptor, estrogen receptor, estrogen related receptor, retinoid $\mathrm{X}$ receptor, aryl hydrocarbon receptor, thyroid hormone receptor and constitutive androstane receptor (Poland and Knutson 1982). It has been observed that same substances activate some of the receptors isoform (i.e. agonist) and block some other isoform (i.e. antagonist). As per other description, some EDCs have involvement with aryl hydrocarbon receptor (AhR). On the other hand, main targets of EDCs are considered as hypothalamico-pituitarythyroid (HPT) axis, hypothalamico- pituitary -adrenal (HPA), and hypothalamico pituitary gonadal (HPG) axis. As per some research work, central nervous system is also affected by EDCs. The AhR mainly belongs to bHLH-PHS protein (Street et al. 2021). This AhR is mainly acts as a ligand activated transcription factor. If the ligand formation is absent, the receptor presents either in the cytoplasmic compartment or in the nuclear compartment (Gronemeyer et al. 2004). On the other side, ligand binding aggravates some cellular changes that guides towards separation of repressive complex which finally proceed towards the gene transcription of NR or AhR gene. Recent data focused that EDCs exposure is not only responsible to damage the exposed generation but also it affect that future generation of that individual and this process is called trans generational inheritance (Diamanti-Kandarakis et al. 2009). The potency of a hormone to activate its receptor is associated with several factors such as amount of synthesised and released hormone by the endocrine gland, way of its transportation through the circulation, amount of the hormone reaches the target organ, and the time span of which hormone can activate its receptor (Beato and SanchezPacheco 2021).

Sometimes, EDCs disturb the endocrine and reproductive systems by mimicking a hormone and its activity. In this case, the EDC acts as the hormone followed by receptor activation in an inappropriate manner. Later on even after the presence of natural hormone the receptor remain blocked with the EDCs. Like this way a single EDC may alter a multiple number of hormone signalling pathways (Lee et al. 2013).

\section{Impact of EDCs on Human Physiology in General}

It has been estimated that about $24 \%$ of human diseases and disorders are caused by environmental factors (Fingerhut et al. 2006) and those factors play a pivotal role in $80 \%$ of deadly diseases such as cardiovascular diseases, cancer and respiratory complications.

\section{EDCs and Endocrine Disease}

The rate of high cases of endocrine diseases are parallel with increased manufacture of chemical goods. Production of plastics increased globally from 50 million tons to about 300 million tons now a days. An additional challenge came forward where humans are exposed to a mixture of chemicals throughout the lifespan by making it more difficult to proof if health effects result from exposure to a few problematic chemicals (Zoeller et al. 2012).

\section{Neurological and Behavioural Disorders}

The pathological conditions including Attention Deficit Hyperactivity Disorder (ADHD) and Autism Spectrum Disorder (ASD), as well as other mood disorders, learning disabilities, depression, executive function deficits and conduct disorders which are a few evidences for impaired neurodevelopment, attention problem, low IQ level, memory failure, and disturbances in motor skills such as writing and reading due to EDCs exposure (Bellanger et al. 2015). 


\section{Obesity and EDCs}

Obesity cases are rising very fast across the globe. Lifestyle which include food style and work style are considered as primary contributors for obesity but on the other side, other evidence showed that several other factors, such as chemical exposures also play an important role for the same (Darbre 2017). The chemicals which are known as "obesogens" are responsible for gaining weight either by altering or reprogramming key parts of the endocrine system especially appetite, metabolism, energy balance that results obesity and associated adverse health outcomes. Research shows that developmental exposure is effective in predisposing an individual to weight gain and its related health hazards including type- 2 diabetes, cardiovascular disease, altered lipid metabolism and altered glucose sensitivity (Shahnazaryan et al. 2019).

\section{Reproductive Disorders and EDCs}

The increased production of EDCs and its link with reproductive physiology is well known and interesting domain today. The increased prevalence in past 50 years regarding hormone-sensitive cancers, early puberty, genital malformations, compromised fertility, decreased sperm counts, and unbalanced sex ratios are partially result of EDCs. Early puberty among girls depends on so many factors including nutrition, stress, and ethnicity, and recently EDCs. Such estrogenic compounds are also associated with uterine fibroids, ovarian dysfunction, and sub fertility in humans and in animal models (Fowler et al. 2011)

\section{Cancer and EDCs}

Cancer is the outcome of the interplay between genetic predisposition and the environment encountered. Few cancers are connected to a single gene along the key role played by the environment. Surprisingly, about 2 in 3 cancer cases are environmentally associated in many ways. The American Cancer Society concluded that most of the cancers are preventable with lifestyle changes i.e. balance diet, optimum physical activity, and smoking. Certain jobs are closely linked with an increased risk of cancers, especially with high load of chemical exposure, including coal mine, rubber industry, paper manufacturing industry, painting, fire-fighting, steel manufacturing company etc. where employees are exposed to different EDCs (Soto and Sonnenschein 2010).

\section{Endocrine glands Specific Biological Effects of EDCs}

\section{EDCs on Adrenal Gland}

Few studies have evaluated the effects of EDC on the adrenal gland, the risks related to exposure to chemicals. This lack of evidence is not easily understandable considering the proper functionality of hypothalamo-pituitaryadrenal (HPA) axis is very essential for human life and it is a very common and general target for different chemicals and drugs. In fact, adrenal glands regulate some biochemical features and structure such as an elevated blood flow, lipophilic structure due to the high content in polyunsaturated fatty acids in cell membrane, and presence of CYP 450 enzymes producing toxic metabolites and free radicals which make them ideal targets for EDCs (Gore et al. 2015; Harvey 2016).

The maximum studied showed the effect of EDCs on the adrenal axis which mainly interfere the biosynthesis and metabolism of steroidal hormones involved. Different EDCs affect the function of aromatase, 5- $\alpha$ reductase, as well as $3-\beta, 11-\beta, 17-\beta$ hydroxysteroid dehydrogenases which play crucial role in metabolic pathways of adrenal steroidogenesis. Synthetic xenoestrogens as EDC sometimes impair adrenal function by inhibiting these above mentioned enzymes (Kabir et al. 2015). Steroid Acute Regulatory Protein (StAR) acts as regulator of the first step of adrenal steroidogenesis is also the target of EDCs (Hampl et al. 2016). There are hundreds of chemicals and drugs interact with adrenal axis where each and every step of steroidogenesis may be affected by the chemical disruptor. (Martinez-Arguelles and Papadopoulos 2015). EDCs partially affect the proper adrenal functions may have severe affect on human health system. In this perspective, bioaccumulation of these endocrine disruptors in adipose tissue might generate a "cocktail," with clinical effects that may be observed only after several years of constant and low-dose exposure. Hexachlorobenzene also acts as chemical disruptor of adrenal gland which is able to alter the normal function corticoid hormone in Wistar strain albino rats (Harvey 2016).

\section{EDCs on Thyroid Gland}

There are many environment derived chemical substances which are responsible to alter iodine absorption by inhibiting the Sodium-Iodide symporter channel (SIS). Perchlorate and thiocyanate are also the EDCs which can able to affect the thyroidal metabolism by inhibiting SIS (Kabir et al. 2015). This channel transports iodine inside thyrocytes i.e. thyroid follicular cells which play a pivotal 
role in the biosynthesis of thyroid hormones (Gore et al. 2015). Elevated levels of perchlorate are found in air-bags, explosives, fertilizers etc. (Kabir et al. 2015). As per survey conducted by National Health and Nutrition Examination (NHAMES) (2001-2008), suggests its presence also in foods, such as milk, vegetables, fruits, eggs in USA (Gore et al. 2015). Cigarette smoke also contains thiocyanate. A study was conducted by Braverman et al. to observe 3,100 subjects exposed to different EDC perchlorate, thiocyanate, and nitrates which resulted a significant decrease of free thyroxine levels, which was more marked in pubertal subjects and it was not associated to increase of TSH levels. Perchlorate, thiocyanate, and nitrates are used extensively and as industrial products but many foods and potable water are contaminated by these chemicals. They can cause a loss of function of NIS binding to NIS and blocks iodide transporter.

No conclusion can be made from current data, but the use of iodine supplementation in pregnancy and in children may protect them from the pathological action of these EDCs. Further studies should investigate the dose-effects relationship in these regards (Braverman et al. 2005).

\section{EDCs on Pituitary Gland}

Several EDCs act on the pituitary gland, therefore influencing the different endocrine axes: as a result, a wide spectrum of clinical manifestations has been associated with exposure to pollutants, such as precocious/delayed puberty (Soriano-Guillen and Argente 2019) and circadian disruption (Sen and Sellix, 2016).The diencephalic system represents a preferential target of EDCs, which may alter proper function of CNS mimicking neurotransmitter actions, beside their ability to bind endocrine receptors (Gore et al. 2015).

\section{EDCs on Reproductive Gland}

Most of EDCs can easily mimics sex gonadal hormones and have the ability to bind with endocrine receptors interfering the signals generated from hormone. Reproductive system is the the most vulnerable endocrine axis to EDCs exposure (Monneret 2017). There are five classes of EDCs capable of showing anti-androgenic properties along with weak estrogenic activity. These classes are (1) drugs or synthetic estrogens (i.e., $17 \beta$ estradiol, diethylstilbestrol), (2) phytoestrogens (i.e., stilbens, cumestans, isoflavonoids, lignans), (3) pesticides (i.e., synthetic pyrethroids, organophosphates, carbamates, organochlorines,); (4) chemicals and plasticizers produced by incomplete combustion of polyvinyl chloride (PVC), paper and putrescible substances (i.e., dioxin); (5) industrial end products (i.e., phenols, flames retardants, dioxins, heavy metals, perfluorooctanoic acid etc.). The EDC exposure should be measured by assessing their effects on the organism, especially in the basic stages of development, when the mammalian organism is extremely sensitive to disturbing agents, exposure might have more pronounced and long-lasting effects (Mnif et al. 2011; Lubrano et al. 2013; Heindel et al. 2015).

Prenatal exposure to EDCS may result in significant changes. Animal models or in vitro systems have been used to investigate the effects of EDC on ovarian development. Literature review have revealed that some EDC can damage the ovary at primary phase by interfering with meiosis, germ cell nest destruction, follicle formation and vitality (Heindel et al. 2015). On the other hand, early postnatal exposure to EDCs may results significant alteration in genetic transcription of somatic cells, altering the proper timing of puberty which may be delayed or anticipated (Schug et al. 2011). Furthermore, EDCs also play a crucial role in decreasing both male and female fertility and causes testicular hypotrophy and polycystic ovarian syndrome (PCOS). (Schug et al. 2011). EDCs are responsible for the onset of testicular dysgenesis syndrome (TDS) (Zoeller et al. 2012; Campion et al. 2012). Impaired spermatogenesis, testicular cancer, undescedent testis and hypospadias may be considered the symptoms of a developmental disorder, due to adverse environmental influences. Experiment showed that TDS is the result of an interruption of embryonal programming and gonadal development during fetal life (Skakkebaek et al. 2001). Generally, in the most severe cases,low level of serum testosterone is observed (Wohlfahrt-Veje et al. 2009) which increased the risk of testicular cancer compared to milder forms has been focused (Skakkebaek et al. 2003; Schug et al. 2011). Vinclozolin, Phthalates, acetaminophen, and polybrominated diphenyl ethers (PBDE) plays a remarkable etiopathogenetic role in the onset of TDS (Schug et al. 2011; Cook et al. 2011). In case of female subject there is a very little evidence observed regarding the effects of EDCs on fertility. Nevertheless, this data seems to suggest that long-term exposure to EDCs may alter female fertility. In particular, EDCs appears to have an etiopathogenetic role in the onset of endometriosis and of ovarian pathology (Caserta et al. 2013a, b). Phthalates, diethylstilbestrol, bisphenol A (BPA), TCCD may be involved in the onset of endometriosis occurring in $10 \%$ of fertile women, causing infertility in 50\% of affected subjects (Schug et al. 2011; Caserta et al. 2013a, b). Ovarian pathology seems to be related to the exposure to $\mathrm{PCB}$, phtalates, atrazine, genistein, BPA, TCDD, parabens, triclosan, dichlorodiphenyltrichloroethane (DDT), and metoxychloride (MXC) (Minguez-Alarcon and Gaskins 2017). Even in males, reproductive function may affected by pollutants and EDCs, but evidence is scarce; EDCs, such as phthalates, 
bisphenol A, biphenyls, and vinclozolin, widespread use of therapeutic drugs, obesity and sedentary life-style may play a crucial role in this supposed decrease of male fertility (Handelsman and Cooper 2013).

\section{EDCs on Male Reproduction}

During the last decades, the adverse effects observed by EDCs in the male reproductive system have been increasing day by day. Although several studies have proved since 1940s that EDCs declines semen quality as the main adverse effect on the male reproductive system, the diverging results from the different study designs were unable to suggest a ultimate conclusion regarding the dose, the magnitude of exposure etc. Similar types of adverse effects have been reported on the male reproductive system that may be connected to exposure of EDC (Nordkap et al. 2012). The latter adverse effects along with the decrease in the quality of semen share similar pathophysiological patterns and are important risk factors for the development of the male fertility disorders. The semen quality has been investigated which an important parameter for detecting the adverse effects is caused by EDCs. In 1980s initial studies were conducted on EDC exposure but did not focus the EDC exposure on the developmental defects in connection with male reproductive system.

The primary hypothesis was framed to delineate the exact cause of deteriorating semen quality in specific human populations. A meta-analysis was conducted by Carlsen et al. (1992) to demonstrate the significant diminution in mean sperm concentrations from 113 to 66 million $/ \mathrm{ml}$. At this period, some additional factors e.g. the methodological aspects of semen analysis, abstinence period, the age and the fertility were considered for decreasing semen quality. In addition, this trend could have been the output of environmental and geographical variations. Swan and coworkers confirmed through the followup study that the afore said findings which were mentioned earlier not the result of biasness, as the different confounding factors were attuned accordingly and an overall diminution in the concentration of sperm was marked annually at 1.5 and $3.1 \%$ of the population in USA and Europe respectively (Swan et al. 2003). On the other hand few studies were conducted in North Europe and particularly in Denmark have provided the supportive evidence that quality of semen can be affected largely by the location of population which is examined (Jorgensen et al. 2001). Subsequent studies that were conducted in Finland by Jorgensen and colleagues in 2001 focused the decrease semen quality in men at the general population in between the period of 1998 and 2006 (Jorgensen et al. 2002). Similar researchers suggested that a large proportion of young men may exhibit suboptimal sperm counts (less than
$40 \mathrm{million} / \mathrm{ml}$ ). The above mentioned epidemiological studies recommend that the different geographical locations of the human population cannot be the own contributing factor for decreasing the sperm count. Thus, alternative environmental factors have to be considered in North Europe for increasing incidence of poor semen quality in specific human populations.

Sperm development and quality is maintained under multiple factors, therefore it may be disrupted at so many points. The hypothalamus generates gonadotropin-releasing hormone $(\mathrm{GnRH})$ that stimulates the anterior pituitary for the synthesis and secretion of gonadotropin, luteinizing hormone ( $\mathrm{LH})$, and follicle-stimulating hormone (FSH) and this incident can be disrupted at any stage. EDCs exposure influence sertoli cell damage either by increasing spermatocyte apoptosis or by up-regulating apoptotic proteins (Zhang et al. 2019). Sertoli cells nourish the development of spermatocytes, absorb excess cytoplasm and accelerate testosterone-linked spermatogenesis. Leydig cell failed to produce testosterone that leads to collapse the testosterone-bound androgen receptor-mediated gene transcription that is necessary for spermatogenesis. Some research focused that EDCs especially BPA inhibits ATP production probably by mitochondrial disruption that results impaired sperm motility (Rahman et al. 2017). EDCs result abnormal hormonal milieu that lead to aneuploidy in sperm and potential transgenerational effects.

Effects of Pesticides as EDCs on Male Reproductive System The occupational exposure to pesticides increases the risk of morphological abnormalities in the sperm of farm workers along with decrease sperm count and viability. Parathion and methyl parathion which are used as pesticides can decrease the sperm concentration by damaging the seminiferous tubules (Perry et al. 2011). The continuous exposure to pesticides decrease the seminal volume along with increases the seminal $\mathrm{pH}$ and abnormal sperm head morphology (Yucra et al. 2008). DDT has specific adverse effects on the male reproductive system due to the disruption of the hypothalamic-pituitary testicular axis and the direct interaction with the sex steroid receptors of the target tissue. Organophosphapte pesticides like malathion exposure of male farmers and/or paraquat resulted in significantly lower values of sperm concentration, $\mathrm{pH}$, mean volumes of sperm motility of spermatozoa, compared with thenon-exposed group (Hossain and D'Souza 2010). The above said results have already been supported by experimental animal studies where both malathion and parathion were shown to diminish the body weights along with the reproductive organ weights and the sperm counts of adult rats. The mode of action was attributed for inducing spermatogenic apoptosis via the modulation of the expression of the apoptotic proteins $\mathrm{Bax}$ and $\mathrm{Bcl}-2$ along 
with concomitant reduction in the different levels of the reproductive hormones LH, FSH and testosterone (Geng et al. 2015).

Effects of Heavy Metal as EDCs on Male Reproductive Health Cadmium toxicity in male reproductive organs is very common and through the contaminated food and environment, the people and animals are exposed. It has been already been reported that due to cadmium exposure testes of animals as well as humans were drastically affected. Cadmium altered the structure of seminiferous tubules, sertoli cells, and the spermatozoa. It also alters the development of leydig cell and its function and leads to the tumor formation in leydig cell. Moreover, cadmium disrupts the vascular system of the testicular tissue. As an inducer of reactive oxygen species, cadmium possibly causes DNA damage and subsequently leads to male subfertility/infertility (Rajendar et al. 2012).

There are several pathways which might be involved in lead-induced impairments of male reproductive health (Vigeh et al. 2011). Lead is the responsible factor for reducing male fertility by decreasing the quality spermatozoa. From direct exposure to high blood lead concentrations, the blood-testis barrier can protect testicular tissue. Moreover, it has been marked that occupational and environmental exposure to lead may drastically affect the hypothalamico-pituitary-testicular axis which leads to impair spermatogenesis. Disturbances in the reproductive axis especially testosterone suppression are most susceptible during the development of puberty. Lead poisoning hampers the process of spermatogenesis and also alters the spermatozoa function. Generation of free radicals due to lead exposure potentially affects viability, count and motility of spermatozoa and also increases DNA fragmentation, and chemotaxis for spermatozoa-oocyte fusion, all of factors can contribute to deterring fertilization (Gandhi et al. 2017).

Arsenic exposure may be the responsible factors for gonadal dysfunction through the diminution of testosterone production, apoptosis and necrosis. Recently, few studies have established that arsenic exposure significantly causes low sperm quality, erectile dysfunction and ultimately causes infertility in men (Pavlova and Atanassova, 2018; Lovakovíc, 2020). Several studies have been established that significant accumulation of arsenic in testes and accessory sex organs, such as epididymis, seminal vesicle, and prostate gland (Sarkar et al. 1991; Pant et al. 2001).

Effects of Food Contact Materials as EDCs on Male Reproductive Status Bisphenol A (BPA) is extensively used in food industries for producing polycarbonate plastic, resin, food packaging, and lacquers for food cans. Human are primarily exposed to BPA through cans and microware containers during heating of food materials and via beverages in polycarbonate bottles due to frequent usage or contact with any acid/alkaline. BPA is very common for our environmental usage and it's levels have been assessed in the majority of individuals. BPA is a known endocrine disruptor (Biles et al. 1997; Moremond et al. 2016). Phthalates are chemicals used in industry that adversely affect human reproductive health. Based on molecular weight and with very different applications they are divided into two distinct groups i.e. high molecular weight compounds (di-2-ethylhexyl phthalate with alkyl chain lengths from 8 to 13 carbons) and low molecular weight compounds [diethyl phthalate, dibutyl phthalate (DBP)]. Phthalates also include three di-(2-ethylhexyl) phthalate (DEHP) metabolites, mono-(2-ethylhexyl) phthalate (MEHP) and two oxidative metabolites, mono-(2-ethyl-5hydroxyhexyl) phthalate (MEHHP), and mono-(2-ethyl-5oxohexyl) phthalate (MEOHP). Phthalates having high molecular weight are primarily used as plasticizers for flooring, wall coverings, consumer products and medical devices (Meeker et al. 2009). Phthalates having low molecular weight are used as solvents in personal-care products and plasticizers for cellulose acetate. Phthalates mainly exposed through ingestion, inhalation, and dermal contact which are considered as important routes of exposure for the general population. After metabolism phthalates are rapidly excreted through urine and faces (Meeker et al. 2009). Nonylphenol (NP) is known as an environmental pollutant that has adverse effects on the spermatogenesis process. Till date the mode of action of Phenols behind the free radicals production has not clearly been established. NP mainly disturbs the balance of antioxidants present in body by increasing the level of reactive oxygen species (ROS). ROS causes oxidative stress and alters the different sperm parameters of rats (Gautam et al. 2018). Spermatozoa have very little cytoplasm which are reached in docosahexaenoic acid, a polyunsaturated fatty acids, susceptible to lipid peroxidation caused by free radicals (Gautam et al. 2018).

Like other cells in the body, spermatazoa has an antioxidant defence system to scavenge the ROS to protect post-meiotic stages such as elongating spermatids and ultimately spermatozoa. In these stages, it is not possible to repair the DNA damage of these cells and as they are very vulnerable. In contrast, when sperms are released from the seminiferous epithelium, they are no longer supported by sertoli cells. One of the most momentous factors in assessing fertility capacity for sperm is motility and viability and these parameters are closely related to the integrity of the sperm membrane (Kumar and Singh, 2015).

Effects of Electronics and Building Materials as EDCs on Male Reproductive Status Polychlorinated biphenyls 
(PCBs), class of persistent organic pollutants which were used widely in the mid-twentieth century. Several decades ago, most of countries banned their production and use.

According to different studies, public and scientific concern about the potential risk of environmental chemicals to male reproductive health has been motivated which focused the downward temporal trends in semen quality and in male testosterone levels (Swan et al. 2003). The evaluation of sperm concentration, motility and viability are used clinically for assessing fertility and also in epidemiological studies as biosensors for toxic effects on male reproductive health. Semen quality may be changed through action on the neuroendocrine system (i.e. the hypothalamic-pituitary-testicular axis), the testis (which includes sertoli and leydig cells as well as the spermatogenic cells), and on post-testicular sites such as the epididymis. PCBs may hamper the reproductive state by interacting with or disturbing one or more of these targets. Recent advances in the measurement of sperm cell DNA integrity (e.g. DNA damage or chromatin fragmentation) and circulating reproductive hormone levels have also led to increased use of these indices in research and clinical practice (Travison et al. 2007).

Effects of Personal Care Products, Medical Tubing as EDCs on Male Reproductive Organ Phthalates, group of chemicals extensively used as personal care products, and medical devices, building materials, consumer products, food storage containers etc. (Schettler 2006). For its massive usage, 18 billions products are produced annually. Owing to the widespread use of phthalates in many different consumer products, humans are exposed daily to these chemicals. It is being observed that phthalates have negative impact on male reproduction. In men, highmolecular-weight phthalates include di (2-ethylhexyl) phthalate (DEHP) were negatively associated with progressive sperm motility (Axelsson et al. 2015).

Moreover, DEHP (20 and $200 \mathrm{mg} / \mathrm{kg} / \mathrm{d}, 500$ and $750 \mathrm{mg} / \mathrm{kg} / \mathrm{d}$ ) has been observed early reproductive senescence in male CD-1 mice by impairing testosterone production, reducing sperm count, motility, viability and ultimately decreasing fertility.

\section{EDCs on female reproductive health}

Biological adverse effects of EDCs with regard to the development of the reproductive system are attributed to folliculogenesis. The primordial follicles convert to primary, pre-antral and antral follicles. There are different types of EDCs such as Bisphenol A (BPA), Methotrexate (MTX), 2,3,7,8-Tetrachlorodibenzo-p-dioxin (TCDD) and phthalates which can interfere the development of the above mentioned types of follicles. EDCs can lead to toxicity and ultimately produces infertility. BPA can be the responsible factors for different female gynocological problem such as polycystic ovary syndrome, fertility problems, and endometriosis (Caserta et al. 2016). On the other hand, MTX inhibits the process of folliculogenesis by rising the expression of the anti-Müllerian hormone in the pre and early antral follicles (Uzumcu et al. 2006), whereas TCDD shows anti-proliferative effects of the ovary of the rat which can ultimately interfere the ovarian steroidogenesis (Karman et al. 2012a, b). Decrease in the primary and secondary follicle numbers and increase in the atretic follicles have been observed in rats having $600 \mathrm{mg} / \mathrm{kg}$ of exposure to the Bis (2-ethylhexyl) phthalate (BEHP) for 60 consecutive days (Xu et al. 2010). Though the toxic effects of EDCs on female reproductive organ in experimental rat are very clear but in case of human populations this association is not directly related to causality. This apparent contradiction occurs mainly on the basis of the severity of exposure which helps to determine the actual dose of daily intake. It is very difficult to determine the dose of human exposure and environmental exposure to EDCs which was compared to laboratory investigations where the different conditions and dose treatment are adequately controlled For example it is being observed that dysfunction of mineralocorticoid receptor was noted in rats due to the exposure of DEHP at the dose range of 100 to $950 \mathrm{mg}$ from gestational day 14 to day 19 (Martinez-Arguelles and Papadopoulos 2015). This dose is considerably greater than the actual exposure of humans to DEHP, whereas the life stage of animal exposure corresponds to early childhood in humans. According to the study of Wang et al., different doses of exposure of $0.5,20$, and $50 \mathrm{~g} / \mathrm{kg}$ of BPA in newborn FVB mice in order to demonstrated fertility reduction as an adverse effect of BPA (Wang et al. 2012).

Research has shown that EDCs alter female reproductive development, fertility capability and also the onset of menopause. A whole set of abnormalities are associated with the EDCs and female reproduction including ovarian dysgenesis syndrome. Some of the EDCs resulted trophoblast and placental function, female hypothalamopitutary gonadal axis, onset of puberty and adult overian function. Side by side EDCs can alter the epigenome in a sexually dimorphic manner that may lead towards the alteration in the germ line especially towards transgenerational manner. EDCs may cause cell cleavage and differentiation, methylation, implantation, cell linage determination, organogenesis at the time of early embryonic development (Wright et al. 2002). Some of the EDCs result many problems that endangered female reproductive health by acting as antagonist endogenous hormone synthesis, bioavailability including reproductive disorders like fetal birth defects, endocrine and metabolic disorders, fetal developmental abnormalities, and even gynecological malignancies (Rao and Kaliwal, 2002). Simultaneously, 
Research shows that EDCs result a huge risk during prenatal and postnatal development when organ and neural systems form. Apart from that, EDCs exposure also result early pregnancy loss, breast cancer, foetal growth restriction and uterine fibroids (Colon et al. 2000).

Effects of Pesticides as EDCs on Female Reproductive Organ Although an extensive amount of research has been conducted to delineate the male infertility due to exposure to pesticides (De et al., 1994), studies among women are insufficient. One reason may be that exposure to pesticides is higher among men, because men usually apply pesticides whereas women get exposed through reentry activities only. On the other hand fertility in women is more difficult to assess than fertility in men. The ovarian cycle of women has not been fully explored as the spermatogenesis in men. Benzene and polychlorinated biphenyls (PCBs) as pesticides can affect the menstrual cycle (Cooper et al. 2005). Other report published that exposure to particular pesticides may initiate ovarian dysfunction. Recently, Farr et al. examined the association between pesticide exposure and menstrual cycle characteristics. From a comparative study it was observed that women who worked with pesticides experiencing long cycles, missed periods, and intermenstrual bleeding compared with women who had never worked with pesticides (Farr et al. 2004). Some pesticides may interfere female hormonal function and thereby cause negative impact on the reproductive system. Most previous studies focused on interference with the estrogen and/or androgen receptor, but the hormonal function can be disrupted in many more ways through pesticide exposure.

The formamidine pesticides e.g. chlordimeform and amitraz have been reported to block norepinephrine binding to the alpha 2-andrenoreceptors (Costa et al. 1988). Norepinephrine is critical for the preovulatory increase in the pulsatile release of $\mathrm{GnRH}$ and the subsequent ovulatory surge of LH (Stoker et al. 2001). In female rat, thiram suppresses the proestrus surge of LH and delays ovulation. Disruption in the timing of the LH surge could alter the viability and the quality of the oocyte and a potential conceptus by pre-ovulatory over-ripeness ovopathy (PrOO) (Jongbloet 2004). Progesterone secretion was inhibited and poor conception occurred after the exposure of malathion at the onset of estrus in cattle (Prakash et al. 1992). Another two studies confirmed the effects of different pesticide exposure on the menstrual cycle. Serum levels of DDT and a metabolite of DDT both found increased in undefined 'menstrual disturbances' (Windham 2002). A study observed that women who are frequently using pesticides experienced longer and irregular menstrual cycles and missed periods compared with women who never used pesticides (Farr et al. 2004).
Effects of Heavy Metal as EDCs on Female Reproductive Health In 1959 the effects of cadmium on the structure and function of ovaries were first observed and reported (Kar et al,1959). High cadmium accumulation in reproductive organs was reported in an experiment with rabbits (Massanyi et al. 1995). Decreased relative volume of growing follicles and increased stroma were found in ovaries of rabbits after cadmium administration (i.p. and p.o.) (Massanyi et al. 1997). Due to the exposure of cadmium, the number of atretic follicles was also significantly elevated. External nuclear membrane undulation and dilatation of perinuclear cistern and endoplasmic reticulum were the most frequently observed ultrastructural change of granulosa, luteal, stroma, and endothelial cells in chronic cadmium exposure (Massanyi et al. 2007). Alterations in the mitochondrial structures were evident in all types of cells studied (Massanyi et al. 2007). A significant diminution in relative volume of primary follicles was observed in cadmium-treated groups (Massanyi et al. 1999).

Chronic lead exposure affects female reproduction mainly by impairing menstruation, delaying conception time reducing fertility potential, and altering hormonal production and circulation, affecting pregnancy and its outcome (Kumar, 2018). Lead toxicity includes miscarriage, early membrane rupture, preeclampsia, pregnancy induced hypertension, and preterm birth and ultimately infertility (Winder, 1993). A review work published in China described the possible links between low-level lead exposure induced adverse effects of the reproductive system. Effects mainly focused as high prevalence rates of menstrual disturbance, spontaneous abortion, and threatened abortion in exposed females (Xuezhi et al. 1992). A comprehensive study was done on female workers having mean age of 32 years employed in a storage battery with a lead exposure period of 7.4 years. The incidence of polymenorrhea, abnormal with prolonged menstruations, and hypermenorrhea was noted in the lead-exposed group, and the incidence of spontaneous abortions was also reported. Authors of this work concluded that the occupational lead exposure results in impairment of the reproductive functions of the females (Tang and Zhu 2003).

Mercury induced reproductive toxicity were first reported many years ago (Colson 1829). Later studies clear the knowledge about the effects of mercury on female reproductive organs. Few reports have been published on the effect of mercury in animal and human female reproductive organs. In case of females, mercury can accumulate in ovaries helps to changes in reproductive behaviour, ovarian failure and ultimately infertility (Bjorklund et al. 2019). Several studies on experimental animals have shown that increased doses of mercury causes potential number of 
Table 1 Some EDCs and their categories

\begin{tabular}{ll}
\hline Category & Example EDCs \\
\hline Pesticides & DDT, Chlorpyrifos, Atrazine \\
Children's Product & Lead, Phthalates, Cadmium \\
Food contact material & BPA, Phthalates, Phenol \\
Electronics and Building materials & Brominated flame retardants, PCBs \\
Personal care products, medical tubing & Phthalates \\
Antibacterials & Triclosan \\
Textiles, Clothing & Perfluorochemicals \\
\hline
\end{tabular}

Abbreviations: $B P A$, bisphenol A; $D D T$, dichloro diphenyl trichloethane; $P C B s$ polychlorinated biphenyls reproductive disorders i.e., infertility, stillbirth, congenital malformations, and spontaneous abortion (Schuurs 1999).

Arsenic, an important water pollutant cum EDC as the exposure of this metalloid results interference in ovarian dysfunctions, uterine deformity and folliculogenesis (Chattopadhyay et al. 2001).This metalloid also known as xenoestrogen cum environmental estrogen that results interference in uterine glandular development (Chatterjee and Chatterji 2010, 2011). Diestrous stage is prolonged in estrous cycle in rat due to arsenic exposure (Chattopadhyay et al. 2001). Arsenic inhibits the ovarian steroidogenesis by desensitizing the estradiol receptors in ovarian follicular cells (Chattopadhyay et al. 2001).
Effects of Food Contact Materials as EDCs on Female Reproduction Food contact materials (FCMs) can be defined as materials that come into contact with food and beverages during food processing, packaging, transport, storage, cooking, or serving. Different types of FCMs, for example, plastics, paper, glass, metal, adhesives, or printing inks, can be used, solely or in combination, to produce food contact articles (FCAs). Phthalates are commonly used as plasticizers in the manufacturing of flexible polyvinyl chloride products. Phthalates can also be found in air, sediments, agricultural and urban soil, wastewater, and natural bodies of water (Berge et al. 2013; Martine et al. 2013).

Phthalates have been shown to alter grrafian follicle development and growth and impair follicle functionality.

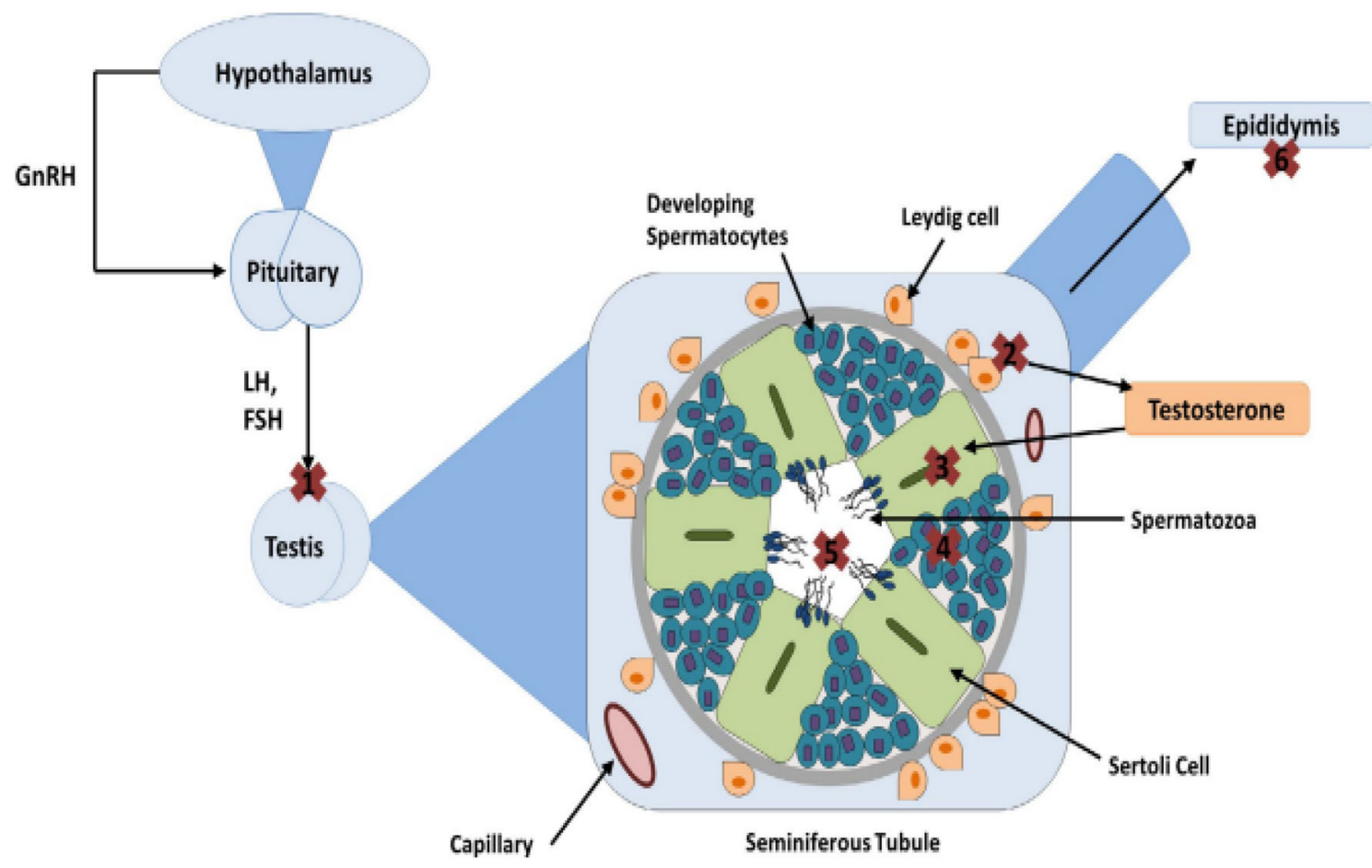

Fig. 1 The mechanism of action of how EDCs can disrupt the sperm quality (Sharma et al., 2020) 
Fig. 2 Proposed model of heavy metal action as EDCs on male infertility

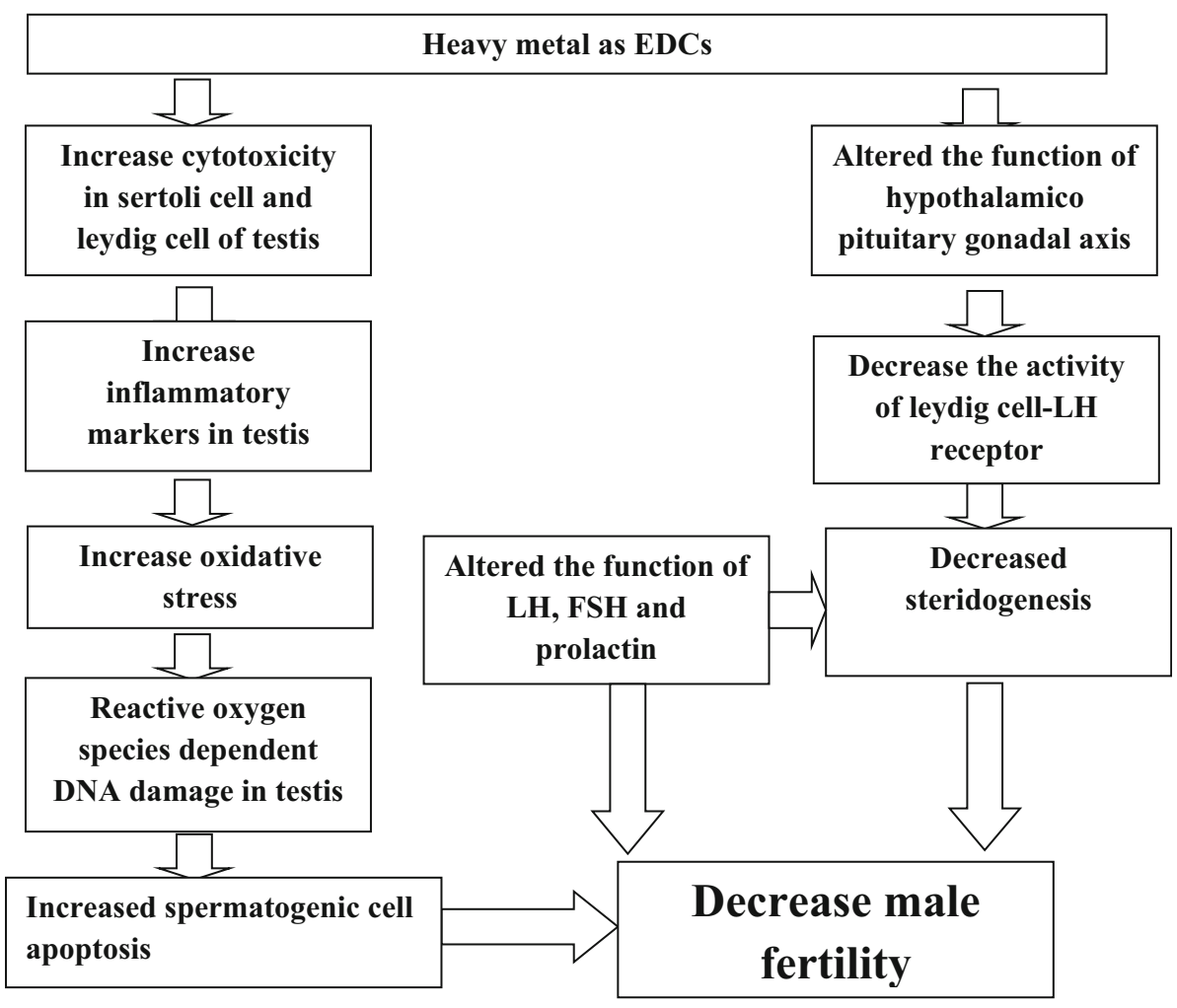

A study has shown that exposure to phthalates may lead to acceleration of primordial follicle recruitment. Specifically, exposure to Di-(2-ethylhexyl) phthalate (DEHP) (20 lg$750 \mathrm{mg} / \mathrm{kg} /$ day) in vivo for 10 to 30 days accelerates primordial follicle recruitment through a mechanism that involves over activation of the phosphatidylinositol 3-kinase (PI3K) pathway (Hannon et al. 2014). Health of follicles was adversely affected by the phthalates. Through oral gavage exposure to DEHP $(600 \mathrm{mg} / \mathrm{kg})$ for $60 \mathrm{con}$ secutive days diminishes primary and secondary follicle numbers and increases atretic follicles (Xu et al. 2010). This may be due to increase of DEHP-induced apoptotic granulosa cells (Xu et al. 2010). Mono-(2ethylhexyl) phthalate (MEHP) has been shown to affect follicle health by inducing oxidative stress by increasing reactive oxygen species levels and disrupting the expression and activity of the antioxidants superoxide dismutase 1 (SOD1) and glutathione peroxidase (GPX), thereby, resulting in (MEHP)induced inhibition of antral follicle growth (Wang et al. 2012).

Bisphenol A (BPA) is a high production volume monomer used for making a wide variety of polycarbonate plastics and resins which is mainly used in food industries. Polycystic ovary syndrome (PCOS) is the very common endocrine disorder among women at the time of reproductive age. PCOS is characterized by insulin resistance, hyperandrogenism and chronic an ovulation. A role for BPA as an endocrine disruptor in the pathogenesis of PCOS has been recently proposed (Tarantino et al. 2013). Several studies reported higher BPA levels in premenopausal women with PCOS when compared to regularly ovulating women. In addition, BPA treatment in rats, both during gestation and during the neonatal period, induced the development of a PCOS-like syndrome in adulthood (Fernández et al. 2010). Moreover, androgen metabolism in the liver is altered by BPA which acts as a potent ligand of sex hormonebinding globulin (SHBG); thus, it can displace androgens from SHBG resulting in increased levels of serum free androgens (Kandaraki et al. 2011).

Effects of Electronics and Building Materials as EDCs on Female Reproductive Status Polychlorinated biphenyls (PCBs), family of industrial compounds which were extensively used as dielectric fluids in electrical transformers and capacitors, as heat exchangers or hydraulic fluids, and in a variety of other commercial applications like building materials. Overall, the studies of reproductive end points in humans are limited; however, the weight of the existing human and animal data suggests that PCBs present a potential reproductive hazard to humans. We observed an association between increasing levels of serum 
PCBs and longer menstrual cycles. There was weaker evidence of an association with irregular cycles, but the effects on cycle length and variability were stronger in the subgroup analyses conducted to explore the effect of outcome or exposure misclassification (Cooper et al. 2005).

Effects of Personal Care Products as EDCs on Female Reproductive Health Cosmetics are used to the body for beautification, cleansing or improving the look. Cosmetic products are consisting of different harmful or toxic chemicals that are capable to cause detrimental effects to the skin. Sometimes, cosmetic manufacturers not only use synthetic elements but also natural products, i.e. rose extract, cane sugar, shea butter, aloe vera etc. which are pocket friendly and less harmful to the consumer. Skincare products such as perfumes, nail polish, make up, etc. stay on the skin for a long period and result massive health hazards (Tarantino et al. 2013). Among other EDCs in personal health care, dibutyl phthalates, butylated hydroxytoluene (BHT), talc, parabens, polyethylene glycols (PEGs), triclosan, formaldehyde cause several complications to women health especially on female reproduction.

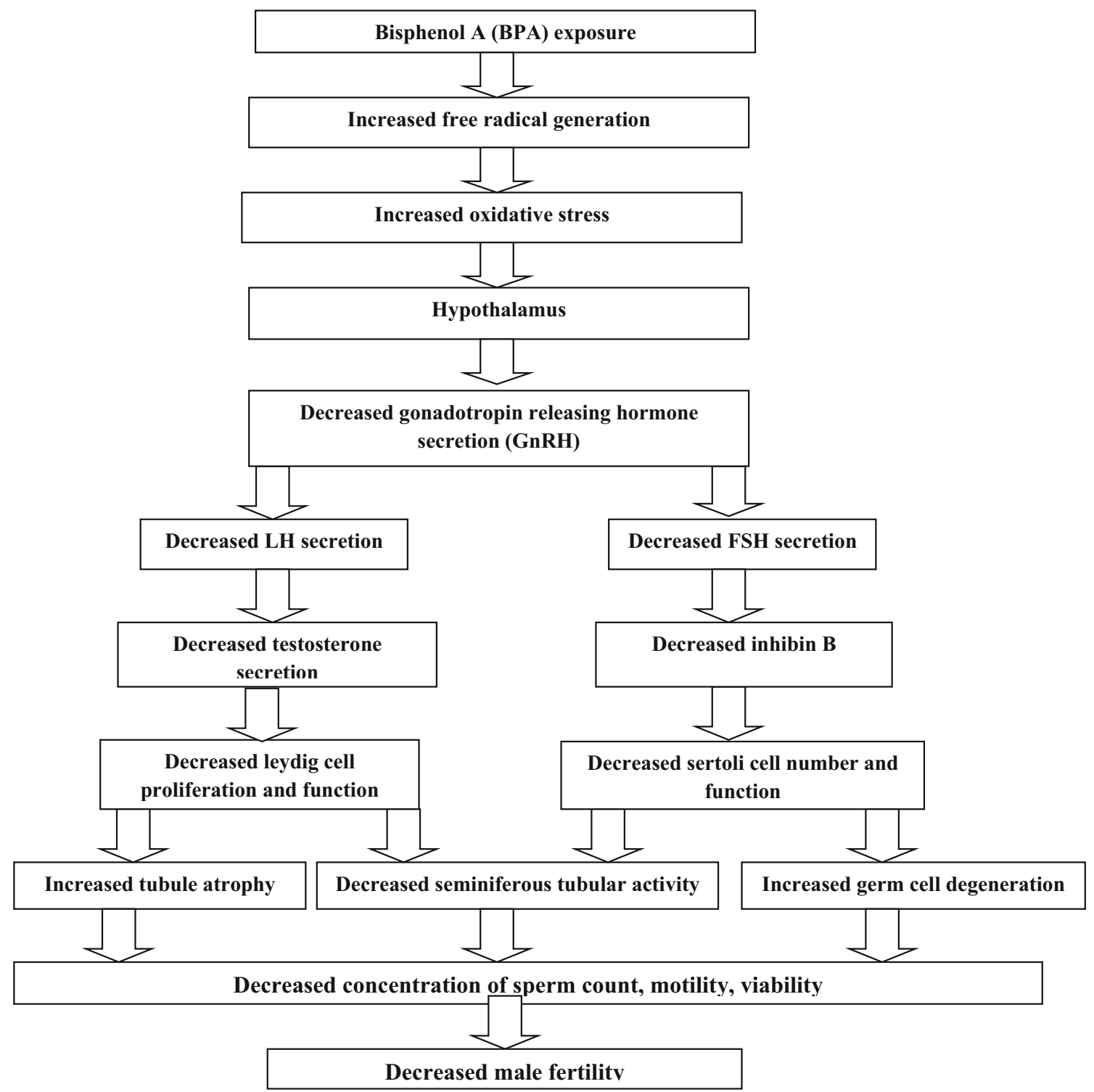

Fig. 3 Proposed action of BPA as EDCs on male infertility 


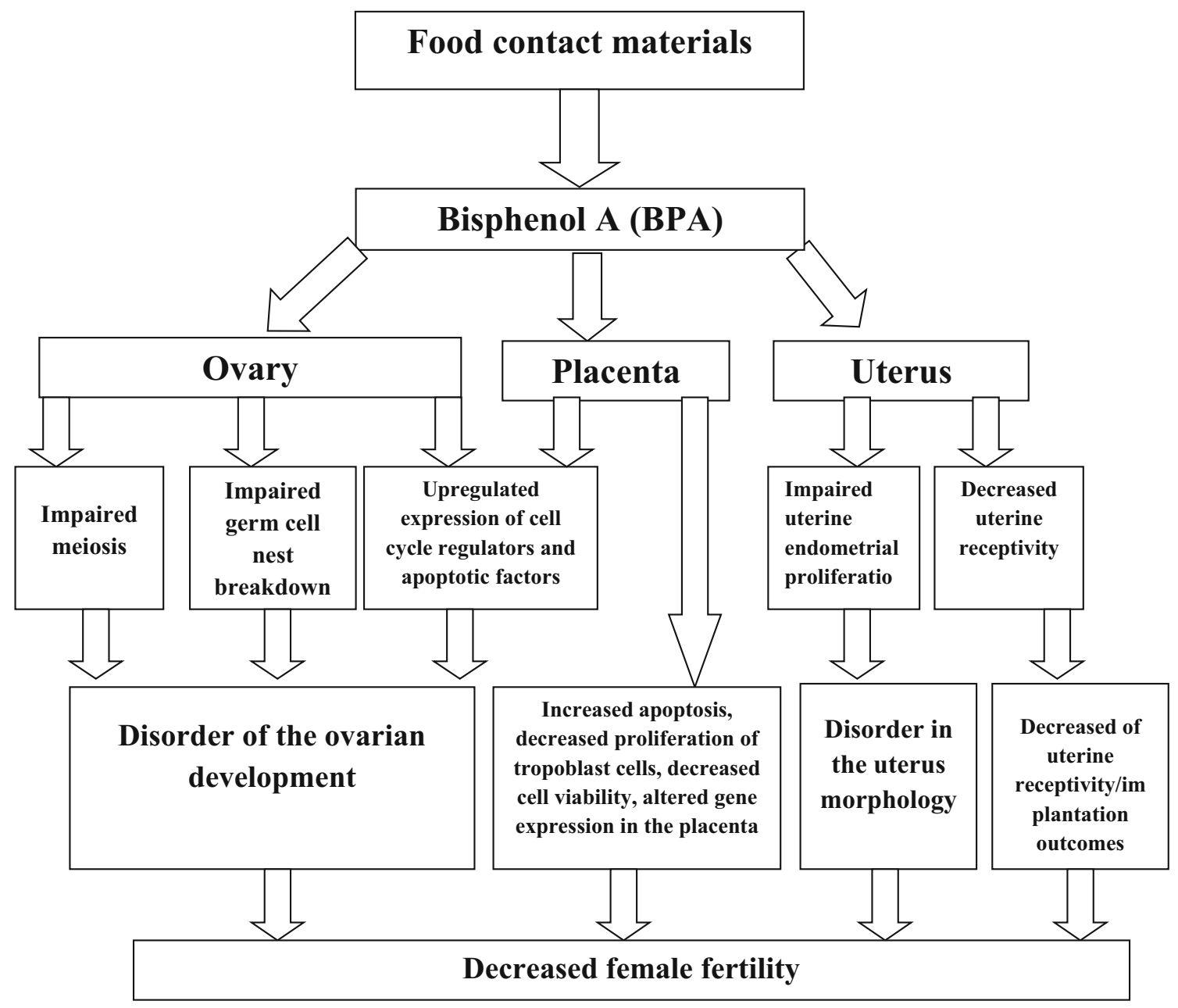

Fig. 4 Proposed model of BPA as EDCs on female infertility

Use of these chemicals led to low count of primordial follicle and increased ovarian cysts. Paraben is another EDCs used in cosmetics. Higher urinary levels of paraben among female were strongly linked with reduced antral follicle count, short menstrual cycle, and decreased the chance of becoming pregnant. Studies showed that paraben exposure diminished the ovarian weight, decreased the number of corpora lutea, increased cystic follicles number, follicular epithelium thinning, altered estrous cycle, and decreased level of plasma estradiol (Kandaraki et al. 2011). Triclosan is an organic lipophilic substance that is generally used in creams, toothpaste, soap or detergent. Studies showed that high concentration of urinary triclosan was linked with low rate of fertilization and implantation which us directly associated with infertility. Formaldehyde is hydrophilic commonly used EDCs in cosmetics. Studies also showed adverse effect on hormones responsible for fertility among female (Stoker et al. 2001).

\section{Conclusion}

From this review we have summarized the mechanistic approach of role of EDCs on human reproductive systems especially on reproductive health of both male and female. In our modern society, the use of EDCs is increasing day by day in spite of its several health hazards (Table 1). But its chronic exposure on human-animal health, their long lasting effect on the environment and of course the remedial approach of these hazards are still in dark. More research data needs to come forwards to give a solution about this problem (Figs. 1, 2, 3, 4).

Open Access This article is licensed under a Creative Commons Attribution 4.0 International License, which permits use, sharing, adaptation, distribution and reproduction in any medium or format, as long as you give appropriate credit to the original author(s) and the source, provide a link to the Creative Commons licence, and indicate if changes were made. The images or other third party material in this article are included in the article's Creative Commons licence, unless 
indicated otherwise in a credit line to the material. If material is not included in the article's Creative Commons licence and your intended use is not permitted by statutory regulation or exceeds the permitted use, you will need to obtain permission directly from the copyright holder. To view a copy of this licence, visit http://creativecommons. org/licenses/by/4.0/.

\section{References}

Beato, M., and A. Sanchez-Pacheco. 2021. Interaction of steroid hormone receptors with the transcription initiation complex. Endocrine Reviews 17: 587-609.

Bellanger, M., B. Demeneix, P. Grandjean, R.T. Zoeller, and L. Trasande. 2015. Neurobehavioral deficits, diseases, and associated costs of exposure to endocrine-disrupting chemicals in the European Union. The Journal of Clinical Endocrinology and MetabolismThe Journal of Clinical Endocrinology and Metabolism 100: 1256-1266.

Berge, A., M. Cladiere, J. Gasperi, A. Coursimault, B. Tassin, and R. Moilleron. 2013. Meta-analysis of environmental contamination by phthalates. Environmental Science and Pollution Research 20: 8057-8076.

Biles, J.E., T.P. McNeal, T.H. Begley, and H.C. Hollifield. 1997. Determination of bisphenol-A in reusable polycarbonate foodcontact plastics and migration to food simulating liquids. Journal of Agricultural and Food Chemistry 45: 3541-3544.

Bjorklund, G., S. Chirumbolo, M. Dadar, L. Pivina, U. Lindh, M. Butnariu, and J. Aaseth. 2019. Mercury exposure and its effects on fertility and pregnancy outcome. Basic \& Clinical Pharmacology \& Toxicology 125: 317-327.

Braverman, L.E., X. He, S. Pino, M. Cross, B. Magnani, and S.H. Lamm. 2005. The effect of perchlorate, thiocyanate, and nitrate on thyroid function in workers exposed to perchlorate long-term. The Journal of Clinical Endocrinology and Metabolism 90: 700-706.

Campion, S., N. Catlin, N. Heger, E.V. McDonnell, S.E. Pacheco, and C. Saffarini. 2012. Male reprotoxicity and endocrine disruption. Exp Suppl. 101: 315-360.

Carlsen, E., A. Giwercman, N. Keiding, and N.E. Skakkebaek. 1992. Evidence for decreasing quality of semen during past 50 years. BMJ 305: 609-613.

Caserta, D., G. Bordi, and F. Ciardo. 2013a. The influence of endocrine disruptors in a selected population of infertile women. Gynecological Endocrinology 29: 444-447.

Caserta, D., G. Bordi, F. Ciardo, R. Marci, C. La Rocca, and S. Tait. 2013b. The influence of endocrine disruptors in a selected population of infertile women. Gynecological Endocrinology 29: 444-447.

Caserta, D., M. Mallozzi, C. Meldolesi, P. Bianchi, and M. Moscarini. 2016. Pregnancy in a unicornuate uterus: a case report. Journal of Medical Case Reports 8: 130.

Chatterjee, A., and U. Chatterji. 2010. Arsenic abrogates the estrogensignaling pathway in the rat uterus. Reproductive Biology and Endocrinology 8: 80-91.

Chatterjee, A., and U. Chatterji. 2011. All-trans retinoic acid protects against arsenic-induced uterine toxicity in female SpragueDawley rats. Toxicology and Applied Pharmacology 257 (2): 250-263.

Chattopadhyay, S., S. Ghosh, J. Debnath, and D. Ghosh. 2001. Protection of sodium arsenite-induced ovarian toxicity by coadministration of L-Ascorbate (Vitamin C) in mature Wistar strain rat. Archives of Environmental Contamination and Toxicolog 41: 83-89.
Colon, I., D. Caro, C.J. Bourdony, C.J. Bourdony, and O. Rosario. 2000. Identificationof phosphate esters in the serum of young Puerto Rican girls with premature breast development. Environmental Health Perspectives 108: 895-900.

Colson, A. 1829. On the influence of mercury on the functions of the uterus. Med Chir Rev. 10: 471-472.

Cook, M.B., B. Trabert, and K.A. McGlynn. 2011. Organochlorine compounds and testicular dysgenesis syndrome: human data. International Journal of Andrology 34: 68-84.

Cooper, G.S., M.A. Klebanoff, J. Promislow, J.W. Brock, and M.P. Longnecker. 2005. Polychlorinated biphenyls and menstrual cycle characteristics. Epidemiology 16: 191-200.

Costa, L.G., G. Olibet, and S.D. Murphy. 1988. Alpha 2-adrenoceptors as atarget for formamidine pesticides: in vitro and in vivo studies in mice. Toxicology and Applied Pharmacology 93: 319-328.

Darbre, P.D. 2017. Endocrine disruptors and obesity. Current Obesity Reports 6: 18-27.

Diamanti-Kandarakis, E., J.P. Bourguignon, L.C. Giudice, R. Hauser, G.S. Prins, and A.M. Soto. 2009. Endocrine-disrupting chemicals: an Endocrine Society scientific statement. Endocrine Reviews 30: 293-342.

Farr, S.L., G.S. Cooper, J. Cai, D.A. Savitz, and D.P. Sandler. 2004. Pesticide use and menstrual cycle characteristics among premenopausal women in the Agricultural Health Study. American Journal of Epidemiology 160: 1194-1204.

Fernández, M., N. Bourguignon, V. Lux-Lantos, and C. Libertun. 2010. Neonatal exposure to bisphenol a and reproductive and endocrine alterations resembling the polycystic ovarian syndrome in adult rats. Environmental Health Perspectives 188: $1217-1222$.

Fingerhut, M., D.I. Nelson, T. Driscoll, M. Concha-Barrientos, K. Steenland, L. Punnett, A. Pruss-Ustun, J. Leigh, C. Corvalan, G. Eijkemans, and J. Takala. 2006. The contribution of occupational risks to the global burden of disease: summary and next steps. La Medicina Del Lavoro. 97: 313-321.

Fiorentino, A., L. Rizzo, H. Guilloteau, X. Bellanger, and C. Merlin. 2017. Comparing $\mathrm{TiO} 2$ photocatalysis and UV-C radiation for inactivation and mutant formation of Salmonella typhimurium TA102. Environmental Science and Pollution Research 24: 1871-1879.

Flint, S., T. Markle, S. Thompson, and E. Wallace. 2012. Bisphenol A exposure, effects, and policy: A wildlife perspective. Australasian Journal of Environmental Management 104: 19-34.

Fowler, P.A., M. Bellingham, K.D. Sinclair, and N.P. Evans. 2011. Impact of endocrine disrupting compounds on female reproductive health. Molecular and Cellular Endocrinology 355: 231-239.

Gandhi, J., R.J. Hernandez, A. Chen, N.L. Smith, Y.R. Sheynkin, G. Joshi, and S.A. Khan. 2017. Impaired hypothalamic-pituitarytesticular axis activity, spermatogenesis, and sperm function promote infertility in males with lead poisoning. Zygote 25: $103-110$.

Gautam, R., K.V. Singh, J. Nirala, N.N. Murmu, R. Meena, and P. Rajamani. 2018. Oxidative stress-mediated alterations on sperm parameters in male Wistar rats exposed to $3 \mathrm{G}$ mobile phone radiation. Andrologia 13: 201-210.

Geng, X., H. Shao, Z. Zhang, J.C. Neg, and C. Peng. 2015. Malathion-induced testicular toxicity is associated with spermatogenic apoptosis and alterations in testicular enzymes and hormone levels in male Wistar rats. Environ. Regulatory Toxicology and Pharmacology 39: 659-667.

Gore, A.C., V.A. Chappell, S.E. Fenton, J.A. Flaws, A. Nadal, and G.S. Prins. 2015. EDC-2: The Endocrine Society's second scientific statement on endocrine-disrupting chemicals. Endocrine Reviews 36: 1-150. 
Gronemeyer, H., J.A. Gustafsson, and V. Laudet. 2004. Principles for modulation of the nuclear receptor superfamily. Nature Reviews Drug Discovery 3: 950-964.

Hampl, R., J. Kubatova, and L. Starka. 2016. Steroids and endocrine disruptors-history, recent state of art and open questions. The Journal of Steroid Biochemistry and Molecular Biology 155: 217-223.

Handelsman, D.J., and T.G. Cooper. 2013. Falling sperm counts and global estrogenic pollution: what have we learned over 20 years? Asian Journal of Andrology 15: 159-161.

Hannon, P.R., J. Peretz, and J.A. Flaws. 2014. Daily exposure to Di(2ethylhexyl) phthalate alters estrous cyclicity and accelerates primordial follicle recruitment potentially via dysregulation of the phosphatidylinositol 3- kinase signaling pathway in adult mice. Biology of Reproduction 90: 136-142.

Harvey, P.W. 2016. Adrenocortical endocrine disruption. The Journal of Steroid Biochemistry and Molecular Biology 155: 199-206.

Heindel, J.J., R. Newbold, and T.T. Schug. 2015. Endocrine disruptors and obesity. Nature Reviews Endocrinology 11: 653-661.

Hossain, F.A., and U. D'Souza. 2010. Effects of pesticide use on semen quality among farmers in rural areas of Sabah, Malaysia. Journal of Occupational Health 52: 353-360.

Jackson, J., and R. Sutton. 2008. Sources of endocrine-disrupting chemicals in urban wastewater, Oakland, CA. Science of the Total Environment 405: 153-160.

Jongbloet, P.H. 2004. Over-ripeness ovopathy: a challenging hypothesis for sex ratio modulation. Human Reproduction 19: 769-774.

Jorgensen, N., A.G. Andersen, F. Eustache, D. Irvine, J.S.S. Suominen, J.H. Petersen, A.N. Andersen, J. Auger, E.H.H. Cawood, and A. Horte. 2001. Regional differences in semen quality in Europe. Human Reproduction 16: 1012-1019.

Jorgensen, N., E. Carlsen, I. Nermoen, M. Punab, J. Suominen, A.G. Andersen, A.M. Andersson, T.B. Haugen, A. Horte, and T.K. Jensen. 2002. East-West gradient in semen quality in the NordicBaltic area: a study of men from the general population in Denmark, Norway, Estonia and Finland. Human Reproduction 17: 2199-2208.

Kabir, E.R., M.S. Rahman, and I. Rahman. 2015. A review on endocrine disruptors and their possible impacts on human health. Environmental Toxicology and Pharmacology 40: 241-258.

Kandaraki, E., A. Chatzigeorgiou, S. Livadas, E. Palioura, F. Economou, M. Koutsilieris, S. Palimeri, D. Panidis, and E. Diamanti-Kandarakis. 2011. Endocrine disruptors and polycystic ovary syndrome (PCOS): elevated serum levels of bisphenol A in women with PCOS. The Journal of Clinical Endocrinology and Metabolism 96: 480-484.

Karman, B.N., M.S. Basavarajappa, Z.R. Craig, and J.A. Flaws. 2012a. 2,3,7,8-Tetrachlorodibenzo-p-dioxin activates the aryl hydrocarbon receptor and alters sex steroid hormone secretion without affecting growth of mouse antral follicles in vitro. Toxicology and Appied Pharmacology 261: 88-96.

Karman, B.N., M.S. Basavarajappa, P. Hannon, and J.A. Flaws. 2012b. Dioxin exposure reduces the steroidogenic capacity of mouse antral follicles mainly at the level of HSD17B1 without altering atresia. Toxicology and Appied. Pharmacology 264: $1-12$.

Khan, N.A., S.U. Khan, S. Ahmed, I.H. Farooqi, M. Yousefi, A.A. Mohammadi, and F. Changani. 2020. Recent trends in disposal and treatment technologies of emerging-pollutants-A critical review. Trends in Analytical Chemistry 122: 115-123.

Kumar, N., and A.K. Singh. 2015. Trends of male factor infertility, an important cause of infertility: A review of literature. Journal of Human Reproductive Sciences 8: 191-196.

Kumar, S. 2018. Occupational and Environmental Exposure to Lead and Reproductive Health Impairment: An Overview. Indian
Journal of Occupational and Environmental Medicine 22: 128-137.

Lee, H.R., E.B. Jeung, M.H. Cho, T.H. Kim, P.C. Leung, and K.C. Choia. 2013. Molecular mechanism(s) of endocrine-disrupting chemicals and their potent oestrogenicity in diverse cells and tissues that express oestrogen receptors. Journal of Cellular and Molecular Medicine 17: 1-11.

Lubrano, C., G. Genovesi, P. Specchia, D. Costantini, S. Mariani, and E. Petrangeli. 2013. Obesity and metabolic comorbidities: environmental diseases? Oxidative Medicine and Cellular Longevity 20: 640-673.

Martine, B., T. Marie-Jeanne, D. Cendrine, A. Fabrice, and C. Marc. 2013. Assessment of adult human exposure to phthalate esters in the urban centre of Paris (France). Bulletin of Environmental Contamination and Toxicology 90: 91-96.

Martinez-Arguelles, D.B., and V. Papadopoulos. 2015. Mechanisms mediating environmental chemical-induced endocrine disruption in the adrenal gland. Frontiers in Endocrinology 6: 29-40.

Massanyi, P., L. Bardos, K. Oppel, S. Hluchy, J. Kovacik, G. Csicsai, and R. Toman. 1999. Distribution of cadmium in selected organs of mice: Effects of cadmium on organ contents of retinoids and beta-carotene. Acta Physiologica Hungarica 86: 99-104.

Massanyi, P., N. Lukac, V. Uhrin, R. Toman, J. Pivko, J. Rafay, Z. Forgacs, and Z. Somosy. 2007. Female reproductive toxicology of cadmium. Acta Biologica Hungarica 58: 287-299.

Massanyi, P., R. Toman, M. Valent, and P. Cupka. 1995. Evaluation of selected parameters of a metabolic profile and levels of cadmium in reproductive organs of rabbits after an experimental administration. Acta Physiologica Hungarica 83: 267-273.

Massanyi, P., V. Uhrín, and M. Valent. 1997. Correlation relationship between cadmium accumulation and histological structures of ovary and uterus in rabbits. Journal of Environmental Science and Health 32: 1621-1635.

Meeker, J.D., S. Sathyanarayana, and S.H. Swan. 2009. Phthalates and other additives in plastics: human exposure and associated health outcomes. Philosophical Transactions of the Royal Society B: Biological Sciences 364: 2097-2113.

Minguez-Alarcon, L., and A.J. Gaskins. 2017. Female exposure to endocrine disrupting chemicals and fecundity: a review. Current Opinion in Obstetrics and Gynecology 29: 202-211.

Mnif, W., A.I. Hassine, A. Bouaziz, A. Bartegi, O. Thomas, and B. Roig. 2011. Effect of endocrine disruptor pesticides: a review. International Journal of Environmental Research and Public Health 8: 2265-2303.

Monneret, C. 2017. What is an endocrine disruptor? Comptes Rendus Biologies 340: 403-405.

Moremond, C., A. Beasly, R. Breton, M. Junghans, R. Laskowski, K. Solemon, and H. Zahner. 2016. Assessing the reliability of the ecotoxicological study: an overview of current needs and approaches. Integrated Environmental Assessment and Management 13: 1-12.

Nordkap, L., U.N. Joensen, J.M. Blomberg, and N. Jorgensen. 2012. Regional differences and temporal trends in male reproductive health disorders: Semen quality may be a sensitive marker of environmental exposures. Molecular and Cellular Endocrinology 355: 221-230.

Pant, N., R. Kumar, R.C. Murthy, and S.P. Srivastava. 2001. Male reproductive effect of arsenic in mice. BioMetals 14: 113-117.

Perry, M.J., S.A. Venners, and X. Liu. 2011. Organophosphorous pesticide exposures and sperm quality. Reproductive Toxicology 31: 75-79.

Poland, A., and J.C. Knutson. 1982. 2,3,7,8-tetrachlorodibenzo-pdioxin and related halogenated aromatic hydrocarbons: examination of the mechanism of toxicity. Annual Review of Pharmacology and Toxicology 22: 517-554. 
Prakash, N., K. Narayana, G.S. Murthy, and N.R. Moudgal. 1992. Honnegowda: The effect of malathion, an organophosphate, on the plasma FSH, 17 beta-estradiol and progesterone concentrations and acetylcholinesterase activity and conception in dairy cattle. Veterinary and Human Toxicology 34: 116-119.

Rahman, Md.S., W.S. Kwon, P.C. Karmakar, S.J. Yoon, B.Y. Ryu, and M.G. Pang. 2017. Gestational exposure to Bisphenol A affects the function and proteome profile of F1 spermatozoa in adult mice. Environmental Health Perspectives 125: 238-245.

Rajendar, B., K. Bharavi, G.S. Rao, P.V. Kishore, P.R. Kumar, C.S. Kumar, and D.S. Kumar. 2012. Protective effect of $\alpha$-tocopherol on biochemical and histological alterations induced by Cadmium in rat testes. Indian Journal of Physiology and Pharmacology 55: 213-220.

Rao, R.P., and B.B. Kaliwal. 2002. Monocrotophos induced dysfunction on estrous cycle and follicular development in mice. Industrial Health 40: 237-244.

Sarkar, M., N.M. Biswas, and D. Ghosh. 1991. Effect of sodium arsenite on testicular $\Delta 5-3 \beta, 17 \beta-H S D$ activities in albino rats: dose and duration dependent responses. Medical Science Research 19: 789-790.

Schettler, T. 2006. Human exposure to phthalates via consumer products. International Journal of Andrology 29: 134-139.

Schug, T.T., A. Janesick, B. Blumberg, and J.J. Heindel. 2011. Endocrine disrupting chemicals and disease susceptibility. The Journal of Steroid Biochemistry and Molecular Biology 127: 204-215.

Schuurs, A. 1999. Reproductive toxicity of occupational mercury. A review of the literature. Journal of Dentistry 27: 249-256.

Sen, A., and M.T. Sellix. 2016. The circadian timing system and environmental circadian disruption: from follicles to fertility. Endocrinology 157: 3366-3373.

Shahnazaryan, U., M. Wojcik, T. Bednarczuk, and A. Kuryłowicz. 2019. Role of obesogens in the pathogenesis of obesity. Medicine 55: 515-527.

Sharma, A., J. Mollier, R.W.K. Brocklesby, C. Caves, C.N. Jayasena, and S. Minhas. 2020. Endocrine disrupting chemicals and male reproductive health. Reproductive Medicine and Biology 19: 243-253.

Skakkebaek, N.E., E. Rajpert-DeMeyts, and K.M. Main. 2001. Testicular dysgenesis syndrome: an increasingly common developmental disorder with environmental aspects. Human Reproduction 16: 972-978.

Skakkebaek, N.E., C.E. Hoei-Hansen, M. Holm, N. Jørgensen, and Meyts E. Rajpert-De. 2003. Association between testicular dysgenesis syndrome (TDS) and testicular neoplasia: evidence from 20 adult patients with signs of maldevelopment of the testis. APMIS 111: 1-11.

Soriano-Guillen, L., and J. Argente. 2019. Central precocious puberty, functional and tumor-related. Best Practice \& Research Clinical Endocrinology \& Metabolism 33: 1-15.

Soto, A.M., and C. Sonnenschein. 2010. Environmental causes of cancer: endocrine disruptors as carcinogenic. Nature Reviews Endocrinology 6: 363-370.

Stoker, T.E., J.M. Goldman, and R.L. Cooper. 2001. Delayed ovulation and pregnancy outcome: effect of environmental toxicants on the neuroendocrine control of the ovary. Environmental Toxicology and Pharmacology 9: 117-129.

Street, M.E., K. Audouze, J. Legler, H. Sone, and P. Palanza. 2021. Endocrine disrupting chemicals: current understanding, new testing strategies and future research needs. International Journal of Molecular Sciences 22: 933-945.

Swan, S.H., C. Brazil, E.Z. Drobnis, F. Liu, R.L. Kruse, M. Hatch, J.B. Redmon, C. Wang, and J.W. Overstreet. 2003. Geographic differences in semen quality of fertile U.S. males. Environmental Health Perspectives 111: 414-420.

Tang, N., and Z.Q. Zhu. 2003. Adverse reproductive effects in female workers of lead battery plants. International Journal of Occupational Medicine and Environmental Health 16: 359-361.

Tarantino, G., R. Valentino, C. Di Somma, V. D’Esposito, F. Passaretti, G. Pizza, V. Brancato, F. Orio, P. Formisano, A. Colao, and S. Savastano. 2013. Bisphenol A in polycystic ovary syndrome and its association with liver-spleen axis. Clinical Endocrinology 78: 447-453.

Travison, T.G., A.B. Araujo, A.B. O'Donnell, V. Kupelian, and J.B. McKinlay. 2007. A population-level decline in serum testosterone levels in American men. The Journal of Clinical Endocrinology and Metabolism 92: 196-202.

Uzumcu, M., P.E. Kuhn, J.E. Marano, A.E. Armenti, and L. Passantino. 2006. Early postnatal methoxychlor exposure inhibits folliculogenesis and stimulates anti-Mullerian hormone production in the rat ovary. Journal of Endocrinology 191: 549-558.

Vigeh, M., D.R. Smith, and P.C. Hsu. 2011. How does lead induce male infertility? Iranian Journal of Reproductive Medicine 9: $1-8$.

Wang, W., Z.R. Craig, M.S. Basavarajappa, K.S. Hafner, and J.A. Flaws. 2012. Mono-(2- ethylhexyl) phthalate induces oxidative stress and inhibits growth of mouse ovarian antral follicles. Biology of Reproduction 87: 152-160.

Windham, G.C. 2002. Exposure to DDT and matabolites in relation to menstrual cycle length among Laotian immigrants. Epidemiology 13: 198-210.

Wohlfahrt-Veje, C., K.M. Main, and N.E. Skakkebaek. 2009. Testicular dysgenesis syndrome: foetal origin of adult reproductive problems. Clinical Endocrinology 71: 459-465.

Wright, C., A.C. Vans, N.P. Evans, P. Duffy, J. Fox, and M.P. Boland. 2002. Effect of maternal exposure to the environmental estrogen, octylphenol, during fetal and/ or postnatal life on onset of puberty, endocrine status, and ovarian follicular dynamics in ewe lambs. Biology of Reproduction 67: 1734-1740.

Xu, C., J.A. Chen, Z. Qiu, Q. Zhao, J. Luo, L. Yang, H. Zeng, Y. Huang, L. Zhang, J. Cao, and W. Shu. 2010. Ovotoxicity and PPAR-mediated aromatase downregulation in female SpragueDawley rats following combined oral exposure to benzo[a]pyrene and di-(2-ethylhexyl) phthalate. Toxicology Letters 199: 323-332.

Xuezhi, J., L. Youxin, and W. Yilan. 1992. Studies of lead exposure on reproductive system: A review of work in China. Biomedical and Environmental Sciences 5: 266-275.

Yucra, S., M. Gasco, and J. Rubio. 2008. Semen quality in Peruvian pesticide applicators: association between urinary organophosphate metabolites and semen parameters. Environmental Health 7: 59-65.

Zhang, P., Y. Zhao, H. Zhang, J. Liu, Y. Feng, S. Yin, and W. Shen. 2019. Low dose chlorothalonil impairs mouse spermatogenesis through the intertwining of Estrogen receptor pathways with histone and DNA methylation. Chemosphere 230: 384-395.

Zoeller, R.T., T.R. Brown, L.L. Doan, A.C. Gore, N.E. Skakkebaek, A.M. Soto, T.J. Woodruff, and F.S. VomSaal. 2012. Endocrinedisrupting chemicals and public health protection: a statement of principles from the endocrine society. Endocrinology 153: 4097-4110.

Publisher's Note Springer Nature remains neutral with regard to jurisdictional claims in published maps and institutional affiliations. 